\title{
A role for dopamine in the processing of drug cues in heroin dependent patients
}

\author{
Ingmar H.A. Franken ${ }^{\mathrm{a}, \mathrm{b}, *}$, Vincent M. Hendriks ${ }^{\mathrm{b}}$, Cornelis J. Stam ${ }^{\mathrm{c}}$, Wim Van den Brink ${ }^{\mathrm{d}}$ \\ ${ }^{a}$ Department of Psychology, Erasmus University Rotterdam, PO Box 1738, 3000 DR Rotterdam, The Netherlands \\ ${ }^{\mathrm{b}}$ Parnassia Addiction Research Center, The Hague, The Netherlands \\ ${ }^{\mathrm{c}}$ Department of Clinical Neurophysiology, VU University Medical Center, Amsterdam, The Netherlands \\ ${ }^{\mathrm{d}}$ Department of Psychiatry Academic Medical Center Amsterdam, Institute for Addiction Research, Amsterdam, The Netherlands
}

Received 9 October 2003; received in revised form 12 February 2004; accepted 12 February 2004

\begin{abstract}
Drug and alcohol dependence are associated with enhanced attention for drug-related stimuli. This cognitive processing bias has been suggested to be related to craving and to represent one of the core mechanisms of addition. The present study tests the hypothesis that enhanced attention for heroin cues is mediated by the dopaminergic system using haloperidol as dopamine antagonist. In a double blind, randomized crossover design, 17 detoxified heroin dependent patients received a single oral dose of haloperidol 2 mg and placebo. Patients performed an Emotional Stroop Task to assess the cognitive processing of drug cues under both conditions. In addition, self-reported craving was assessed. In the haloperidol condition, patients performed better on the Emotional Stroop Task than in the placebo condition. However, no effect of haloperidol on subjective craving was found. These findings provide preliminary indications that attentional bias in heroin dependent humans is mediated by dopaminergic mechanisms.
\end{abstract}

(C) 2004 Elsevier B.V. and ECNP. All rights reserved.

Keywords: Human; Craving; Dopamine; Haloperidol; Attentional bias; Heroin dependence

\section{Introduction}

Recent studies provide evidence that drug dependent subjects exhibit an excessive attentional focus on drugrelated cues (for a review see Franken, 2003). This attentional bias, which has been found to be present in alcohol (Johnsen et al., 1994), heroin (Franken et al., 2000; Lubman et al., 2000), and nicotine dependence (Ehrman et al., 2002; Waters and Feyerabend, 2000), may promote craving and ultimately relapse (Cox et al., 2002; Waters et al., 2003b). Recently, theoretical accounts have been developed that posit enhanced attentional processing of motivational relevant cues is the 'core process' of addiction (Robinson and Berridge, 1993). Although the presence of this attentional bias in heroin addiction has been adequately demonstrated using behavioral (Franken et al., 2000) and neurophysiological measures (Franken et al., 2003; Franken et al., in press),

\footnotetext{
* Corresponding author. Department of Psychology, Erasmus University Rotterdam, PO Box 1738, 3000 DR Rotterdam, The Netherlands. Tel.: +31-10-408-9563; fax: +31-10-408-9009.

E-mail address: franken@fsw.eur.nl (I.H.A. Franken).
}

research into the neurobiological underpinnings of this bias is scarce. Recently, advances have been made in knowledge on the neural basis of these processing biases (Elliott et al., 2002). These authors found that the medial and orbital prefrontal regions play a role in mediating the interaction between mood and cognition in affective disorder. However, the psychopharmacology of processing biases has not been studied before. It has been suggested that the dopamine signal serves to draw attention to salient events in general (Gray et al., 1997). In a review, Schultz (1998) shows that the processing of appetitive stimuli in animals is dopaminergically regulated. More specifically, Robinson and Berridge (1993) hypothesize that activation of dopaminergic activity in the cortico-striatal reward circuit by cues which signal reward could contribute to the excessive focusing on stimuli, which lead to further drug use. Although there is some evidence for this hypothesis in animal studies (see e.g. Ito et al., 2000, 2002; Phillips et al., 2003), human studies investigating the role of dopamine in drug-related cognitions are not known. One of the basic assumptions of Schultz and the Robinson and Berridge Incentive-sensitization model, that the role of dopaminergic neurotransmission is to direct 
attention towards reward-indicating stimuli, will be tested in the present study. Based on the Incentive-sensitization model, Franken (2003) hypothesized that cue-elicited dopamine release is directly related to an enhanced attentional bias for drug cues in abstinent heroin users.

In the present study, this hypothesis will be tested by a dopamine antagonist challenge. The hypothesized excessive dopamine release will, at least partly, be prevented by a single dose of a typical dopamine antagonist, haloperidol 2 $\mathrm{mg}$. In a double blind randomized crossover design, 17 detoxified heroin dependent patients received a single oral dose of haloperidol $2 \mathrm{mg}$ and placebo. Patients performed an Emotional Stroop Task under both conditions, and selfreported craving was assessed. In previous studies haloperidol (4 mg) has been used successfully in decreasing cueelicited cocaine craving (Berger et al., 1996). Because this 4 $\mathrm{mg}$ dose may result in drowsiness, which may distort subtle attentional processes, and to minimize the occurrence of extrapyramidal side-effects, we chose for a single dose of 2 $\mathrm{mg}$ haloperidol. This dose has been successfully used in modifying higher cognitive functions (Peretti et al., 1997). Specifically, it has been found that $2 \mathrm{mg}$ haloperidol is a sufficient dose to induce modulation in selective and involuntary attention (Ahveninen et al., 2000; Kahkonen et al., 2001). Nordstrom et al. (1992) demonstrated that D2 receptor occupancy $3 \mathrm{~h}$ after oral administration of a single dose of $2 \mathrm{mg}$ haloperidol was $18 \%$ and $52 \%$ after $6 \mathrm{~h}$. In the present study, $4 \mathrm{~h}$ were between admission and testing which, according to the Nordstrom study, should result in an about $30 \%$ D2 receptor occupancy.

\section{Methods}

\subsection{Subjects}

Eighteen eligible male heroin dependent subjects were recruited from a detoxification unit of a substance abuse program (Parnassia Mental Health Care). One subject was excluded because a different Stroop Task was used; the results of 17 patients were analyzed. All participants had been abstaining from illicit drug use (including heroin and cocaine) for a minimum of 2 weeks. None of the subjects were positive on urine drug tests, which are employed routinely in the detoxification unit. At the time of testing none of the subjects was taking prescribed or non-prescribed medications other than the research medication. Candidates were excluded from the study if one of the following conditions was present: withdrawal symptoms, lifetime use of neuroleptic medication, schizophrenia, affective disorder, mental retardation, significant somatic disorders such as Parkinson disease (or symptoms). All subjects were male in order to rule out gender effects. Of the subjects, six had lower education, nine had middle education, and three had higher education (according to the Dutch educational system). The mean age of the sample was 35.7 years (S.D. $=6.4$ ), which is typical for heroin users in treatment settings in the Netherlands (Ouwehand et al., 1999). Drug use characteristics are displayed in Table 1. Most heroin dependent subjects $(n=17)$ had a history of additional cocaine use and most subjects had ever been in a methadone maintenance program $(n=12)$. The study was approved by the Ethical Committee of the institution in which the work was performed.

\subsection{Stimuli}

Neutral and heroin words were presented in random order. The Stroop Tasks consisted of 10 heroin-related words (such as dope and heroin) and 10 neutral, transportrelated words (such as train and bike). For complete word list and selection criteria of the words is referred to Franken et al. (2000). The two categories of words were matched for the number of letters and syllables (in Dutch). Each word was presented in four times in a different color (red, yellow, blue, green) in a random order resulting in 40 neutral and 40 heroin words in total.

\subsection{Apparatus}

All stimulus material was presented on an IBM G50 monitor, controlled by an IBM P-100 PC that also registered the manual responses. The presentation of the stimuli was programmed in ERTS language (Beringer, 1994). A stimulus word in one of the four colors was presented on the screen and remained on the screen until responding (maximum $3000 \mathrm{~ms}$ ). The order of presentation was random, with the restriction that a specific word category was not presented more than four consecutive times. The inter-trial interval was set at $1000 \mathrm{~ms}$.

\subsection{Self-report instruments}

Instant craving was measured by the 14-item desire for drug questionnaire (DDQ) (Franken et al., 2002). This

Table 1

Drug use characteristics of the heroin dependent group $(n=17)$

\begin{tabular}{|c|c|}
\hline & Mean \pm S.D. \\
\hline $\begin{array}{l}\text { Age of first heroin use } \\
\quad(>3 \text { times a week) }(n=17)\end{array}$ & $22.6 \pm 7.0$ \\
\hline $\begin{array}{l}\text { Age of first cocaine use } \\
\quad(>3 \text { times a week })(n=17)\end{array}$ & $20.8 \pm 5.6$ \\
\hline $\begin{array}{l}\text { Age of first methadone use } \\
\quad(>3 \text { times a week) }(n=12)\end{array}$ & $24.8 \pm 5.3$ \\
\hline Total years of heroin use $(n=17)$ & $8.8 \pm 6.7$ \\
\hline Total years of cocaine use $(n=17)$ & $10.4 \pm 6.3$ \\
\hline Total years of methadone use $(n=12)$ & $4.6 \pm 6.4$ \\
\hline $\begin{array}{l}\text { Number of days of heroin use in } \\
\text { month before detoxification }(n=17)\end{array}$ & $26.7 \pm 8.6$ \\
\hline $\begin{array}{l}\text { Number of days of cocaine use in } \\
\text { month before detoxification }(n=17)\end{array}$ & $25.8 \pm 8.5$ \\
\hline $\begin{array}{l}\text { Number of days of methadone use in } \\
\text { month before detoxification }(n=12)\end{array}$ & $14.0 \pm 12.8$ \\
\hline
\end{tabular}


questionnaire was adapted from the desires for alcohol questionnaire (DAQ) (Love et al., 1998) for use in heroin addicts. It measures instant (now) craving and consists of three subscales. The three subscales are: desire and intention to use drugs, negative reinforcement (the relief of negative states), and perceived control over drug-use. The three subscales have good reliability and concurrent validity (Franken et al., 2002).

Drug use severity was assessed by means of the drug use scale of the addiction severity index (ASI) (Hendriks et al., 1989). Questions in this scale refer to the different types of drugs used, the numbers of days used, and duration of use.

The 32 item version of the Profile of Mood States (POMS, De Groot, 1992; McNair et al., 1992) questionnaire was used in order to investigate changes in mood states. This version of the POMS consists of five subscales labeled depression, anxiety, tension, vigor, and fatigue.

Subjectively experienced physiological symptoms were investigated using the physiological symptoms questionnaire (PSQ, Powell et al., 1992). This scale contains a three-item subscale on drug-positive symptoms (pleasant feeling in stomach, itchy nose and feeling high) and a sevenitem subscale on drug negative symptoms (feeling cold, runny nose, muscular tension, aches, gooseflesh, yawning restlessness). Each item is scored on a four-point scale.

\subsection{Procedure}

Eligible subjects were asked to participate in a study concerning the attentive processing of heroin words. They were informed that participation involved the intake of $2 \mathrm{mg}$ haloperidol, conducting a reaction time task with heroin words, and craving measurements. The participants received a remuneration of 50 euro. All subjects provided written informed consent. The experiment started with a short explanation of the procedure and informed consent was obtained. Personal data and history of drug use (ASI) were recorded by the experimenter. Then the subject completed the pre-exposure questionnaires. Subjects were sitting at a table, approximately, $80 \mathrm{~cm}$ from the monitor. Instructions were to attend to the color of the words and to ignore the content. Furthermore, they were instructed to press the corresponding colored button as quick as possible, without making mistakes. In both sessions, a practice trial of 80 colored words (the word "test") was run first in order to get used to the buttons. Then the emotional Stroop Task was started. After having completed the two sessions, subjects received their financial compensation and there was a check by the experiment-leader whether the craving levels were not unacceptable high. If so, a cool-down-talk was provided until craving levels were decreased to an acceptable level.

\subsection{Data analysis}

In an attempt to reduce the influence of outliers, given the high likelihood that these were artifacts, and to correct for skewness, trials with response time (RT's) more than 3 S.D. above and below the individual mean RT for each condition were excluded for all analyses (3.1\% of all trials). Cutoff criterion of 3 S.D.'s from the mean has been a common and robust method in eliminating outliers from RT data (Ratcliff, 1993). RTs were averaged within each Word type condition for each subject. RTs were analyzed using a 2 (Word Type) $\times 2$ (Condition) repeated measurements ANOVA. Results from the Mauchly Sphericity test indicated that the assumption of sphericity was not violated. Pairwise comparisons were made using ordinary $t$-tests. In addition, error rates were also analyzed with a 2 (Word Type) $\times 2$ (Condition) repeated measurements ANOVA. Differences between the placebo and haloperidol-session in self-reported craving, mood, and physical symptoms were analyzed using a paired $t$-test.

\section{Results}

\subsection{Effects of haloperidol on cognitive processing}

The mean RTs on the two word categories by condition are displayed in Fig. 1. There was a main effect of medication condition: RT's in the haloperidol condition were significantly faster than in the placebo condition, $F(1,16)=5.18, P=0.037$. No significant main effect was found for Word type, $F(1,16)=0.56, P=0.466$. In addition, an interaction effect was observed, $F(1,16)=0.4 .72$, $P=0.045$. This indicates that individuals in the haloperidol condition were faster to indicate word color of the heroin words, thereby suggesting that, within a heroin dependent

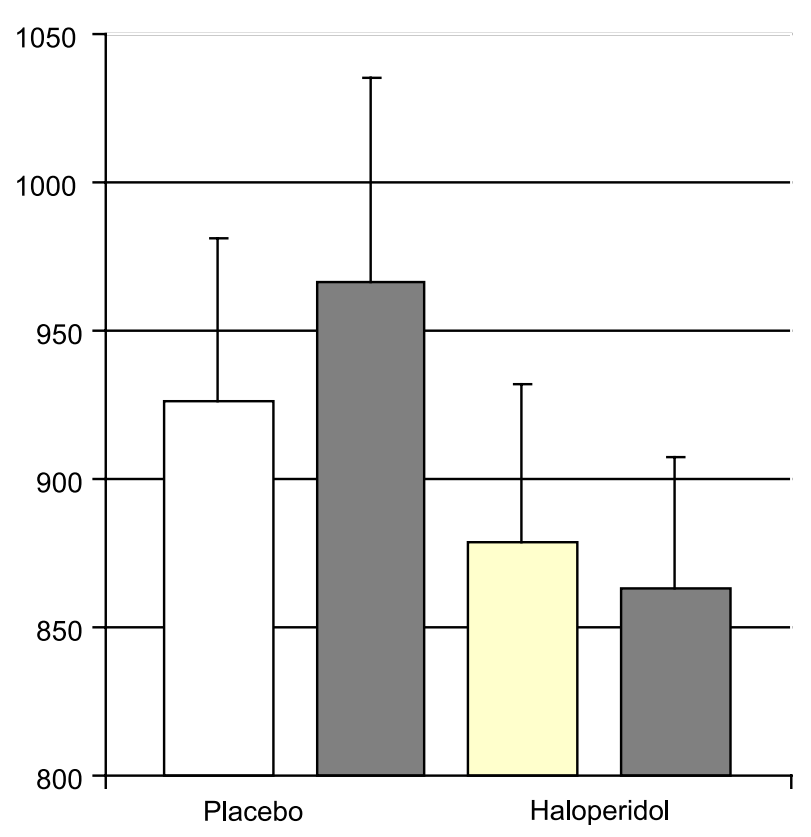

Fig. 1. Mean responding times (in ms) on neutral (white bars) and heroin words (gray bars) by medication condition $(n=17)$, including error bars. 
Table 2

Mean (S.D.) values of self-reported craving, mood, and physical symptoms after placebo and haloperidol, including $t$-values $(n=17)$

\begin{tabular}{lccc}
\hline & Placebo & Haloperidol & $t$-value \\
\hline DDQ desire & $1.8(1.3)$ & $2.1(1.1)$ & -1.50 \\
DDQ negative & $4.3(2.2)$ & $4.4(2.0)$ & -0.60 \\
$\quad$ reinforcement & & & \\
$\quad$ craving & & & \\
DDQ control & $2.1(1.7)$ & $2.1(1.5)$ & 0.10 \\
POMS depression & $6.3(5.3)$ & $9.2(7.0)$ & $-2.65^{*}$ \\
POMS anxiety & $7.1(6.1)$ & $7.7(6.7)$ & -0.56 \\
POMS fatigue & $8.5(7.3)$ & $10.5(7.7)$ & -1.12 \\
POMS vigor & $9.8(4.3)$ & $8.8(4.7)$ & 0.80 \\
POMS tension & $6.9(4.8)$ & $7.5(4.5)$ & -0.65 \\
PSQ positive symptoms & $1.4(0.3)$ & $1.4(0.4)$ & -0.21 \\
PSQ negative symptoms & $1.9(0.6)$ & $2.0(0.8)$ & -0.59 \\
\hline
\end{tabular}

* $P=0.017$; other values not significant at the 0.05 level.

population, Heroin Stroop interference decreases after ingestion of a dopamine antagonist.

Within the placebo session, the percentages of error rates of neutral and heroin words were $1.7 \%$ and $3.8 \%$, respectively. Within the haloperidol-session, the percentages of error rates of neutral and heroin words were $1.7 \%$ and $3.6 \%$, respectively. In the ANOVA for error rates, no significant main or interaction effect could be observed, all $F_{\mathrm{S}}<1.0$.

\subsection{Effects of haloperidol on self-reported craving, mood and physical symptoms}

Mean values of the DDQ, POMS and PSQ are displayed in Table 2. The only significant effect on the self-reported measures was the observation that patients reported more depressive symptoms during the haloperidol-session compared to the placebo session. In addition, in none of the patients extrapyramidal side-effects, or other visible sideeffects could be observed.

\subsection{Validity checks}

Order effects were not significant. A 2 (session) $\times 2$ (word type) ANOVA showed that, overall, subjects did not perform different on the first versus second session, $F(1,16)=1.59$, $P=0.226$. In addition, no session $\times$ word type interaction effect could be observed, $F(1,16)=0.107, P=0.748$.

In addition, patients were asked whether they believed they received the first or the second day the active medication. Forty-one percent of the patients guessed correctly. This guess is not different from the 50\% chance level, $t(16)=-7.2, P=0.48)$. Thus it may be concluded that the conditions were indeed double blind.

\section{Discussion}

The present study shows that attentional processes in abstinent heroin dependent patients can be modified by a low dose of haloperidol. It can be speculated that abstinent heroin abusers are less distracted by heroin words by this low dose of haloperidol. The found significant interaction effect provides a first indication to assume that a D2 dopamine antagonist decreases attentional focusing on drug cues in humans.

Our finding provides indirect evidence for the assumption that the perception of drug-related cues results in increased in dopamine activity (Di Chiara, 1999; Robinson and Berridge, 1993). The improvement on the general selective attention with haloperidol in heroin users can be interpreted as evidence that the dopamine levels were increased during the Stroop Task with placebo. This finding is in line with the sensitization theory, which claims that enhancements of the incentive salience of drug-related cues, which is present in drug dependent patients, is dopaminergically mediated. Furthermore, it provides preliminary evidence for the hypothesis that dopamine triggers the brain's attention towards motivational significant stimuli (Franken, 2003; Robinson and Berridge, 1993).

In addition to an interaction effect, overall selective attention was also improved by haloperidol compared to placebo. One explanation of this effect is that the heroin words in the Stroop Task elicit a general distracting state and a general focusing on heroin cues which results in increased overall reaction times. For example, it is known that if drugrelated words are followed by neutral words, so-called "carry-over" effects appear which result in an increase in RTs to neutral words (Waters et al., 2003a). This effect is generally present in mixed randomized word sequences of emotional Stroop Tasks (Waters et al., submitted for publication) and is specifically present in the heroin Stroop Task that is used in this study (Franken et al., 2000; Waters et al., submitted for publication). This carry-over effect results subsequently in a general increase in reaction times on the task. Probably, this carry-over effect captures the difficulty of disengaging attention from emotional salient stimuli such as heroin (Waters et al., 2003a) and may therefore reflect an incremental component of attentional bias (Waters et al., submitted for publication). The present findings show faster reaction times during the haloperidol-session compared to placebo, thereby suggesting that haloperidol attenuates this difficulty of disengaging. In addition, the finding that haloperidol improves overall attentional functioning in heroin dependent patients can be explained by the ability of haloperidol to normalize a dopamine-induced disruption in attention (Brockel and Fowler, 1995). It is known that both increased or decreased dopamine activity results in disruption of attentional functions in healthy humans (Nieoullon, 2002; Shelley et al., 1997). In addition, normalizing the DA transmission in patients with dopamine abnormalities will result in improvements of cognitive functions (Nieoullon, 2002). In the present study, we observed a general improvement on the Stoop task. This observation is in line with studies on other psychiatric disorders in which an excessive dopamine activity is present, such as schizophrenia. In 
schizophrenics dopamine antagonists results also in improvement of selective attention (Kumari et al., 1999).

We were not able to confirm the a priori hypothesis that dopamine antagonist reduce cue-elicited craving. Furthermore, this finding not in accordance with the hypothesis that attentional bias and craving are closely related to each other (Franken, 2003). According this hypothesis, a decrease in attentional bias should result in a decreased craving (and vice versa). The finding that haloperidol $2 \mathrm{mg}$ did not decrease craving also not consistent with a previous study of Berger et al. (1996) who did find a decrease in cueelicited cocaine craving after a $4 \mathrm{mg}$ doses of haloperidol. A hypothetical explanation for this contrast may be that the 2 $\mathrm{mg}$ dose of haloperidol does induce a minimal decrease in both attentional bias and craving. However, the minimal change in attentional bias may be detected by sensitive RTparadigms, unlike the hypothetical decrease in craving, which remains undetected by self-report. Further studies using a higher dose of haloperidol should investigate this hypothetical explanation. Although $2 \mathrm{mg}$ haloperidol was not able to reduce self-reported craving, it was able to increase feelings of depression. This increase of depression is a known side-effect of haloperidol (Ramaekers et al., 1999). Another possibility is the status of the reliability of self-reported craving. Taking the self-reported measures as "golden-standard" for investigating motivational construct is at least "problematic" (Marissen et al., submitted for publication; Miller, 1996; Sayette et al., 2000). In the later study was found that self-reported heroin craving is obscured by "social desirable" answering.

There were some limitations to the present study. First, no healthy control group was used to compare with, only within-group comparisons were made. However, a previous studies using the same task did show that healthy controls do not exhibit an attentional bias for heroin-related words (Franken et al., 2000). Therefore, it is not likely that the cognitive improvement would also be present in non-dependent subjects. Second, the present sample-size is rather small, more studies using larger sample-sized are needed. Furthermore, it is not known why not all patients show the haloperidol effect therefore, more research on the individual differences should be conducted. Third, in the present study we used the mixed version of the Stroop Task (heroin and neutral words in mixed order). This obscured probably the Stroop effect. Future studies may use blocked versions (first all neutral words, then all heroin words) of the Stroop Task which will probably result in larger differences. Fourth, we did not have a record of the nicotine status of the participants. However, it is reasonable to assume that their nicotine status was not different between the two testing conditions (placebo vs. haloperidol). Fifth, the data were marginally significant. We employed additional non-parametric statistics (Wilcoxon signed ranks test) to test the robustness of our findings. In the placebo condition, the subjects had enhanced reaction times on the heroin cues compared to the neutral cues $(z=-2.296, P=0.022)$. This indicates that heroin cues capture more attention than neutral cues. However, in the haloperidol condition, no difference was found between the reaction times on the heroin cues compared to the neutral cues $(z=-0.355$, $P=0.723)$. This indicates that in the haloperidol condition, heroin cues do not capture more attention than neutral cues. The findings of the non-parametric statistics underline our original findings.

It would be premature to speculate about clinical implications of the present study. It is known that haloperidol produces side-effects in neuroleptic naive subjects on higher single dose admissions (Ramaekers et al., 1999) and also on the longer term (Rosebush and Mazurek, 1999), which decreases the usefulness of haloperidol in the treatment of addictive behaviors. However, the present study provides important clues on how dopamine is involved in human addiction. It provides an indication that dopamine enhances the attentional processing of drug cues in human heroin abusers.

\section{Acknowledgements}

Supported by grant \# 985-01-005 of the Dutch Organization for Scientific Research (NWO).

\section{References}

Ahveninen, J., Kahkonen, S., Tiitinen, H., Pekkonen, E., Huttunen, J., Kaakkola, S., Ilmoniemi, R.J., Jaaskelainen, I.P., 2000. Suppression of transient $40-\mathrm{Hz}$ auditory response by haloperidol suggests modulation of human selective attention by dopamine D2 receptors. Neurosci. Lett. 292, 29-32.

Berger, S.P., Hall, S., Mickalian, J.D., Reid, M.S., Crawford, C.A., Delucchi, K., Carr, K., Hall, S., 1996. Haloperidol antagonism of cue-elicited cocaine craving. Lancet 347, 504-508.

Beringer, J., 1994. ERTS: a flexible software tool for developing and running psychological reaction time experiments on IBM PCs. Behav. Res. Meth. Instrum. Comp. 26, 368-369.

Brockel, B.J., Fowler, S.C., 1995. Effects of chronic haloperidol on reaction time and errors in a sustained attention task: partial reversal by anticholinergics and by amphetamine. J. Pharmacol. Exp. Ther. 275, $1090-1098$.

Cox, W.M., Hogan, L.M., Kristian, M.R., Race, J.H., 2002. Alcohol attentional bias as a predictor of alcohol abusers' treatment outcome. Drug Alcohol Depend. 68, 237-243.

De Groot, M.H., 1992. Psychometrische aspecten van een stemmingsschaal: de verkorte POMS (Psychometric aspects of a mood questionnaire: the Dutch short POMS). Gedrag Gezondheid (Behav. Health) 20, 46-51.

Di Chiara, G., 1999. Drug addiction as dopamine-dependent associative learning disorder. Eur. J. Pharmacol. 375, 13-30.

Ehrman, R.N., Robbins, S.J., Bromwell, M.A., Lankford, M.E., Monterosso, J.R., O’Brien, C.P., 2002. Comparing attentional bias to smoking cues in current smokers, former smokers, and non-smokers using a dotprobe task. Drug Alcohol Depend. 67, 185-191.

Elliott, R., Rubinsztein, J.S., Sahakian, B.J., Dolan, R.J., 2002. The neural basis of mood-congruent processing biases in depression. Arch. Gen. Psychiatry 59, 597-604.

Franken, I.H.A., 2003. Drug craving and addiction: integrating psycholog- 
ical and neuropsychopharmacological approaches. Prog. Neuro-Psychopharmacol. Biol. Psychiatry 27, 563-579.

Franken, I.H.A., Kroon, L.Y., Wiers, R.W., Jansen, A., 2000. Selective cognitive processing of drug cues in heroin dependence. J. Psychopharmacol. 14, 395-400.

Franken, I.H.A., Hendriks, V.M., Van den Brink, W., 2002. Initial validation of two opiate craving questionnaires: the obsessive compulsive drug use scale (OCDUS) and the desires for drug questionnaire (DDQ). Addict. Behav. 27, 675-685.

Franken, I.H.A., Stam, C.J., Hendriks, V.M., van den Brink, W., 2003. Neurophysiological evidence for abnormal cognitive processing of drug cues in heroin dependence. Psychopharmacology 170, 205-212.

Franken, I.H.A., Hulstein, K.P., Stam, C.J., Hendriks, V.M., van den Brink, W., in press. Two new neurophysiological indices of cocaine craving: evoked brain potentials and cue modulated startle reflex. J. Psychopharmacol.

Gray, J.A., Young, A.M., Joseph, M.H., 1997. Dopamine's role. Science $278,1548-1549$.

Hendriks, V.M., Kaplan, C.D., Van Limbeek, J., Geerlings, P., 1989. The addiction severity index: reliability and validity in a Dutch addict population. J. Subst. Abuse Treat. 6, 133-141.

Ito, R., Dalley, J.W., Howes, S.R., Robbins, T.W., Everitt, B.J., 2000. Dissociation in conditioned dopamine release in the nucleus accumbens core and shell in response to cocaine cues and during cocaine-seeking behavior in rats. J. Neurosci. 20, 7489-7495.

Ito, R., Dalley, J.W., Robbins, T.W., Everitt, B.J., 2002. Dopamine release in the dorsal striatum during cocaine-seeking behavior under the control of a drug-associated cue. J. Neurosci. 22, 6247-6253.

Johnsen, B.H., Laberg, J.C., Cox, W.M., Vaksdal, A., Hugdahl, K., 1994. Alcoholic subjects' attentional bias in processing of alcohol-related words. Psychol. Addict. Behav. 8, 111-115.

Kahkonen, S., Ahveninen, J., Jaaskelainen, I.P., Kaakkola, S., Naatanen, R., Huttunen, J., Pekkonen, E., 2001. Effects of haloperidol on selective attention: a combined whole-head MEG and high-resolution EEG study. Neuropsychopharmacology 25, 498-504.

Kumari, V., Soni, W., Sharma, T., 1999. Normalization of information processing deficits in schizophrenia with clozapine. Am. J. Psychiatry $156,1046-1051$

Love, A., James, D., Willner, P., 1998. A comparison of two alcohol craving questionnaires. Addiction 93, 1091-1102.

Lubman, D.I., Peters, L.A., Mogg, K., Bradley, B.P., Deakin, J.F.W., 2000. Attentional bias for drug cues in opiate dependence. Psychol. Med. 30, $169-175$.

Marissen, M., Franken, I.H.A., Hendriks, V.M., van den Brink, W., submitted for publication. The effect of social desirability on self-reported heroin craving and physiological reactivity in a cue exposure paradigm.

McNair, D., Lorr, M., Droppelman, L.F., 1992. CA: Educational and Industrial Services, San Diego.

Miller, G.A., 1996. How we think about cognition, emotion, and biology in psychopathology. Psychophysiology 33, 615-628.
Nieoullon, A., 2002. Dopamine and the regulation of cognition and attention. Prog. Neurobiol. 67, 53-83.

Nordstrom, A.L., Farde, L., Halldin, C., 1992. Time course of D2-dopamine receptor occupancy examined by PET after single oral doses of haloperidol. Psychopharmacology 106, 433-438.

Ouwehand, A.W., van Alem, V., de Vetten, L., Boonzajer, S., 1999. Ladis Annual Report IVV, Houten.

Peretti, C.S., Danion, J.M., Kauffmann-Muller, F., Grange, D., Patat, A., Rosenzweig, P., 1997. Effects of haloperidol and amisulpride on motor and cognitive skill learning in healthy volunteers. Psychopharmacology 131, 329-338.

Phillips, P.E., Stuber, G.D., Heien, M.L., Wightman, R.M., Carelli, R.M., 2003. Subsecond dopamine release promotes cocaine seeking. Nature $422,614-618$.

Powell, J., Bradley, B., Gray, J., 1992. Classical conditioning and cognitive determinants of subjective craving for opiates: an investigation of their relative contributions. Br. J. Addict. 87, 1133-1144.

Ramaekers, J.G., Louwerens, J.W., Muntjewerff, N.D., Milius, H., de Bie, A., Rosenzweig, P., Patat, A., O’Hanlon, J.F., 1999. Psychomotor, cognitive, extrapyramidal, and affective functions of healthy volunteers during treatment with an atypical (amisulpride) and a classic (haloperidol) antipsychotic. J. Clin. Psychopharmacol. 19, 209-221.

Ratcliff, R., 1993. Methods for dealing with reaction time outliers. Psychol. Bull. 114, 510-532.

Robinson, T.E., Berridge, K.C., 1993. The neural basis of drug craving: an incentive-sensitization theory of addiction. Brain Res. Rev. 18, 247-291.

Rosebush, P.I., Mazurek, M.F., 1999. Neurologic side effects in neuroleptic-naive patients treated with haloperidol or risperidone. Neurology 52 , $782-785$.

Sayette, M.A., Shiffman, S., Tiffany, S.T., Niaura, R.S., Martin, C.S., Shadel, W.G., 2000. The measurement of drug craving. Addiction 95, S189-S210.

Schultz, W., 1998. Predictive reward signal of dopamine neurons. J. Neurophysiol. 80, 1-27.

Shelley, A.-M., Catts, S.V., Ward, P.B., Andrews, S., Mitchell, P., Michie, P., McConaghy, N., 1997. The effect of decreased catecholamine transmission on ERP indices of selective attention. Neuropsychopharmacology $16,202-210$.

Waters, A.J., Feyerabend, C., 2000. Determinants and effects of attentional bias in smokers. Psychol. Addict. Behav. 14, 111-120.

Waters, A.J., Sayette, M.A., Wertz, J.M., 2003a. Carry-over effects can modulate emotional Stroop effects. Cogn. Emot. 17, 501-509.

Waters, A.J., Shiffman, S., Sayette, M.A., Paty, J.A., Gwaltney, C.G., Balabanis, M.H., 2003b. Attentional bias predicts outcome in smoking cessation. Health Psychol. 22, 378-387.

Waters, A.J., Sayette, M.A., Franken, I.H.A., Schwartz, J.E., submitted for publication. Carry-over effects may capture a component of attentional bias. 